\title{
Testing Psychometrics of Healthcare Empowerment Questionnaires (HCEQ) among Iranian Reproductive Age Women: Persian Version
}

\author{
Bahram Mohebbi ${ }^{1}$, Azar Tol ${ }^{2}$, Elham Shakibazadeh ${ }^{3 *}$, Mahdi Yaseri ${ }^{4}$, Maryam \\ Sabouri $^{5}$, Feleke Doyore Agide ${ }^{6,7}$
}

OPEN ACCESS

Citation: Bahram Mohebbi, Azar Tol, Elham Shakibazadeh, Mahdi Yaseri, Maryam Sabouri, Feleke Doyore Agide. Testing Psychometrics of Healthcare Empowerment Questionnaires (HCEQ) among Iranian Reproductive Age Women: Persian Version. Ethiop J HealthSci.2017;28(3):341.

doi:http://dx.doi.org/10.4314/ejhs.v28i3.12

Received: December 13, 2017

Accepted: December 15, 2017

Published: May 1, 2018

Copyright: (C) 2018 Bahram, M. et al This is an open access article distributed under the terms of the Creative Commons Attribution License, which permits unrestricted use, distribution, and reproduction in any medium, provided the original author and source are credited.

Funding: Tehran University Medical Sciences

Competing Interests: The authors declare that this manuscript was approved by all authors in its form and that no competing interest exists.

Affiliation and Correspondence:

${ }^{1}$ Rajaie Cardiovascular Medical and

Research Center, Iran University of Medical

Sciences ,Tehran, Iran

${ }^{2}$ Department of Health Education and

Promotion, School of Public Health, Tehran

University of Medical Sciences, Tehran,

Iran

${ }^{3}$ Department of Health Education and Promotion, School of Public Health, Tehran University of Medical Sciences, Tehran, Iran

${ }^{4}$ Department of Epidemiology and Biostatistics, School of Public Health, Tehran University of Medical Sciences, Tehran, Iran

${ }^{5}$ Department of Health Education and Promotion, School of Public Health, Tehran University of Medical Sciences, Tehran, Iran

${ }^{6}$ Department of Health Education and Promotion, School of Public Health, International Campus, Tehran University of Medical Sciences, Tehran, Iran

${ }^{7}$ Department of Public Health, College of Medicine and Health Sciences, Wachemo University, Ethiopia

*Email: shakibazadeh@tums.ac.ir

\section{ABSTRACT}

BACKGROUND: Producing high quality data needs an accurate measurement in any fields of study. This study aimed to test psychometrics of the Persian version Healthcare Empowerment Questionnaire (HCEQ) in relation to personal care among Iranian reproductive age women and to validate the instrument for future use.

METHODS: A cross-sectional study was conducted on 549 reproductive age women in a health centers affiliated to Tehran University of Medical Sciences producing a response rate of $100 \%$. Content validity was established using translation and backtranslation procedures, pilot testing, and getting views of expert panel. Construct validity was measured using explanatory factor analysis. Cronbach's alpha was used to measure internal consistency, and intra-class correlation coefficients were used to confirm stability.

RESULTS: The results indicated that explanatory factor analysis of 10 items in three dimensions explained $63.2 \%$ of the total variance. Validity and reliability of the 10-items of $\mathrm{HCEQ}$ with two response scales (perception of control and motivation of being empowered) assessed for internal quality showed the reliability of internal consistency $(\alpha=0.70 ;$ range $=0.62-0.76)$. The correlation between convert (10 items) and apparent (3 factors) variables was 0.5 times higher than the revealed convergent validity.

CONCLUSION: The findings of this study supported the reliability and validity of the Persian version of HCEQ to assess the degree of individual empowerment in relation to personal healthcare and services among reproductive age women. Therefore, the HCEQPersian version could be a useful, comprehensive, and culturally sensitive scale for assessing healthcare empowerment among reproductive age women.

KEYWORDS: Healthcare Empowerment Questionnaire (HCEQ), Reproductive Age, Women, Reliability, Validity 


\section{INTRODUCTION}

In recent years, various experts including health professionals have increasingly used the term empowerment. It is used to express information, skills, interpretation, emotions and values properly in life $(1,2)$. Health empowerment focuses on responsibility and ability of individuals to maintain their health (1). According to the World Health Organization (WHO), individuals, families and communities should be empowered in order to promote their health (3). Especially, women play a central role in health empowerment of their families. Women's health assures the health of children and families (4).

Various research findings showed that women's health care empowerment is affected by several social, economic, and cultural factors including poverty, economic dependency, discrimination and violence against women. This is manifested by restricted power and authority in life, and wide continuum of women needs to health care (5).

The international conference on development and population specified women's empowerment as a cornerstone of achieving desirable health especially reproductive health $(3,5-7)$. Women's healthcare empowerment brings better life satisfaction, improved interaction with others and the environment, and improved abilities to confronthealth problems (8-12).

To date, a variety of instruments exist to assess healthcare empowerment (13-15). However, there are few questionnaires that address multi-dimensional perspectives on psychometrics of healthcare empowerment of women. For instance, the questionnaire developed and validated by Gagnon et al in 2006 on healthcare empowerment measures the degree of individual empowerment in relation to personal healthcare and services. Psychometric findings have shown that the HCEQ appears to be useful in advancing knowledge about individual empowerment in relation to personal healthcare and services (16). The study on women's healthcare empowerment is very limited in Iran, and due to this reason, few validated questionnaires exist. Therefore, the study aimed to translate the HCEQ into Persian and broadly test its psychometric properties as regards women's healthcare empowerment among Iranian women to present a validated tool to Persian language countries.

\section{MATERIALS AND METHODS}

Study design, research population and sample:

A cross-sectional study was conducted on 549 reproductive age women in health centers affiliated to Tehran University of Medical Sciences through multi-level cluster sampling method to provide a maximum of ten respondents per item on HCEQ (16). Individuals aged 18-45 years and had active medical files in the clinics were eligible to participate in the study.

Data collection: Data were collected from November 2016 to February 2017 by four trained public health students using intervieweradministered questionnaires. A questionnaire package including a cover letter, questions on socio-demographics and the 10-HCEQ items were given to those who consented. In the qualitative section, the translation and backtranslation process of the original version of HCEQ-10 items was made. Then, translation and backtranslation were reviewed by an independent group of experienced researchers and linguistics (five researchers and two bilingual translators) in order to achieve a modified version of the original questionnaire. They confirmed that the translated version of HCQ-10 Persian version (HCEQ-10/PV) was culturally and linguistically fitted for Persian women in reproductive age. They also approved that wording and phrasing accordingly. Delphi method was used to check agreement on appearance and content of the translated version. Later, the HCEQ-10/PV was sent to eight academic members who were experts in instrument development and women's health. The evaluation of the experts indicated that the analyzed version and the original one were completely similar in content.The content validity was checked to ascertain whether the content of the questionnaire was appropriate and relevant to the purpose of the study. The modified version transferred to the independent expert panel 
included four members, which were responsible to develop the final version of HCEQ-10/PV. In conclusion, content validity of HCEQ-10/PV was checked by experts in the various fields including one gynecologist, two healthcare providers in women's health and two health education and promotion specialists. The original HCEQ-10/PV and the translated version were re-sent to each panel of bilingual member by the expert panel. The content validity was re-evaluated by panel members to rate the level of each item in two response scales: a) perception of control with regard to healthcare and services using 4-point scale $(1=$ "not at all" to $4=$ "extremely"); and b) motivation evaluation as the importance to being $(1=$ "not important at all" to $4=$ "extremely important"). Furthermore, the panel was requested inquired to comment on individual items in relation to the accuracy, simplicity, method, and cultural relevance of the final translated version. The panel recommended some brief to initiate a change and provide modified version of the questionnaire. Later, a pilot study was conducted on the modified version and necessary corrections were made accordingly. Exploratory factor analysis (EFA) was used to assess construct validity. Both Bartlett's Chi-squared test of sphericity and the Kaiser-Meyer-Olkin (KMO) test of sampling adequacy were carried out to see the suitability of analysis (17). The principal component extraction method with Varimax rotation with Kaiser Normalization was used to analyze grouped data descriptively (18). The following criteria were considered: 1) Eigen value $>1$ (19); 2) Varimax rotation loading level greater than 0.5 to assess whether an item loaded on one factor or the others (20) and 3) significance of description of the factor structure (21). The significance level was set at $\mathrm{p}<0.01$. The reliability was tested for internal consistency with Cronbach's alpha value. Moreover, intercorrelation between items was tested with the Pearson correlation, and half split technique was determined by measuring the intra-class correlation coefficient (ICC) to assess inter-rater consistency of the raters. The benchmark for the ICC was as $>0.75=$ excellent, between 0.40 and $0.75=$ moderate, and $<0.40=$ poor (22).
Involvement in decision making is increasing one's authority and responsibility over the resources and decisions that affect one's life. Involvement in interaction is women's involvement through communication and sharing information with others. Involvement in control over is the exercise of women's real choice and gaining increased control over on their matters.

Ethics: The study was approved by the Ethics Committee of Tehran University of Medical Sciences (Ethical code: IR.TUMS.SPH.REC.139501435). The purpose of the study was informed to participants and written informed consent was obtained. Confidentiality was assured by informin that the information recorded was used for research purposes only and that no personal details would be recorded or produced on any documentation related to the study.

\section{RESULTS}

Five hundred forty-nine respondents participated in the study with the overall response rate of $100 \%$. The mean age was $31 \pm 5.2$ ranging from 25 to 35. Accordingly, the majority of reviewers identified general shape of the questionnaire as organized, well-arranged and easy for clarity and ease of understanding (Table 1).

Table 1: Health-related characteristics among study participants among Iranian reproductive age women from 2016-2017 $(\mathrm{n}=549)$

\begin{tabular}{lll}
\hline Variables & Options & Number(\%) \\
\hline Age in years & $<25$ & $93(16.9)$ \\
& $25-35$ & $291(53.0)$ \\
& $\geq 35$ & $165(30.1)$ \\
Employment & Public employee & $85(15.5)$ \\
& Private employee & $75(13.7)$ \\
& Household & $389(70.8)$ \\
Level of education & Up to diploma & $98(17.8)$ \\
& Diploma and & $451(82.2)$ \\
Marital status & higher & \\
& Married & $526(95.8)$ \\
Frequency of receiving & Unmarried & $23(4.2)$ \\
health care services & $<2$ & $131(23.9)$ \\
(months) & & \\
& $2-6$ & $262(47.7)$ \\
Past Medical History & $>6$ & $156(28.4)$ \\
& Yes & $37(6.7)$ \\
& No & $532(93.3)$ \\
\hline
\end{tabular}


The internal consistency of the questionnaire was examined through determination of the Cronbach's alpha value, inter-correlation between the scales, and the half split technique. The Cronbach's alpha value for the entire questionnaire was 0.70 (0.62 to 0.76). Spearman correlation coefficient was used to demonstrate the reliability of item domains such as "involvement in decisions (items 8,9,10)", "involvement in interaction (items 4,5,6,7)" and "degree of control (items 1,2,3)" and their Cronbach's $\alpha$ were $0.62, \quad 0.71$ and 0.76 respectively.

The Bartle's test of 10 items $\left(c^{2}=0.79 ; \mathrm{df}=45\right.$; $\mathrm{p}<0.001)$ indicated that the inter-item correlation was sufficient. The KMO measured that the sampling adequacy was $0.79 ; p<0.001$. EFA was performed with Varimax rotation matrix, which extracted three factors and explained $63.2 \%$ of the total variance. The first factor named "Degree of control items" consisted of three questions. This factor explained $35.0 \%$ of the bulk of variability of the original data. The second factor called "Involvement in interaction" comprised four questions. The third factor, "Involvement in decisions", consisted of three questions. The percentage of variability in the data interpretation was $12.3 \%$ (Table 2, Table 3, Table 4).

Table 2: Descriptive statistics of HCEQ-10/PV and its subscales among Iranian reproductive age women from 2016-2017 ( $\mathrm{n}=549)$

\begin{tabular}{|c|c|c|c|c|}
\hline Domain & $\begin{array}{l}\text { Number of } \\
\text { items }\end{array}$ & Means \pm SD & $\begin{array}{l}\text { Eigen } \\
\text { Value }\end{array}$ & $\begin{array}{l}\text { Variance } \\
(\%)\end{array}$ \\
\hline Degree of control items & 3 & $44.17 \pm 20.11$ & 3.50 & 35.08 \\
\hline Involvement in interaction & 4 & $44.79 \pm 17.35$ & 1.62 & 16.22 \\
\hline Involvement in decisions & 3 & $51.45 \pm 18.61$ & 1.23 & 12.32 \\
\hline
\end{tabular}

Table 3: Item analysis and reliability of the HCEQ-10/PV after back translation among Iranian reproductive age women from 2016-2017 $(n=549)$

\begin{tabular}{lllll}
\hline Subscales & items & Mean \pm SD & Cronbach $\boldsymbol{\alpha}$ & ICC \\
\hline Degree of control item & 1 & $8.08 \pm 3.90$ & & \\
& 2 & $7.52 \pm 3.50$ & 0.766 & 0.766 \\
Involvement in interaction & 3 & $7.28 \pm 3.55$ & & \\
& 4 & $7.62 \pm 3.71$ & & 0.716 \\
& 5 & $7.50 \pm 3.38$ & 0.716 & \\
Involvement in decisions & 6 & $7.82 \pm 3.46$ & & \\
& 7 & $7.94 \pm 3.61$ & & 0.622 \\
\hline
\end{tabular}

\section{DISCUSSION}

This study tried to evaluate important components of psychometric properties (validity and reliability) of healthcare empowerment questionnaires among women. In the study, the translation of the HCEQ10/PV had no problems with conveying intended meanings of words. Generally, the Persian wording in the translated HCEQ was clear, unambiguous, and easy to understand.
In this study, with regard to reliability analysis, a Cronbach alpha value of $<0.70$ indicates low correlation among items. The Persian version had a Cronbach alpha of $0.70(0.62-0.76)$. These findings are quite similar with and sometimes better than those of previous studies (16). The good internal consistency indicates that the HCEQ-10/PV items measure the same concepts of healthcare empowerment. Furthermore, the high alpha value for the HCEQ-10/PV factors indicated the good internal consistency of the instrument (17).

DOI: http://dx.doi.org/10.4314/ejhs.v28i3.12 
Table 4: Shows exploratory factors and explained variance after rotation for HCQE-10/PV among Iranian reproductive age women from 2016-2017 $(\mathrm{n}=549)$.

\begin{tabular}{|lllll|}
\hline & Number & of & \multicolumn{2}{c|}{ Factors } \\
\cline { 5 - 5 } Subscales & items & $\mathbf{1}$ & $\mathbf{2}$ & $\mathbf{3}$ \\
\hline Degree of control items & 2 & 0.829 & & \\
& 1 & 0.806 & 0.831 & \\
Involvement in interaction & 3 & 0.731 & 0.823 & \\
& 6 & & 0.787 & \\
& 7 & & 0.572 & 0.827 \\
Involvement in decisions & 5 & & & 0.780 \\
& 4 & & & 0.567 \\
Eigen Value & 10 & & 1.62 & 1.23 \\
Variance & 9 & 3.50 & 16.22 & 12.32 \\
\hline
\end{tabular}

In this study, the half-split technique showed a high correlation as measured by ICC which exceeded 0.70 . Correlation between factors showed positivity with all domains. It is important to note that, "degree of control items" domain had greater Eigen value than the others which were the same with the original scale. The lowest Cronbach $\alpha$ was calculated in "involvement in decisions" domain. This can be related to introversion, low educational status and skills level, traditional believes and women dependency in receiving healthcare. Therefore, the application of this questionnaire for women health research by is far important to measure psychological viewpoints in behavior modification as it has been highly recommended by numerous researchers (22-26). Furthermore, the questionnaire was found to cover a wide continuum from individual empowerment to social empowerment by the focus on individual ability to gain access to, understand and use information from personal healthcare to maintain good health (16). Similarly, this study revealed the importance of Persian version of the questionnaire among women to measure individual's ability to make the best decision regarding healthcare services in healthcare settings, having efficient interaction with healthcare providers and select better healthcare choices. This study remarked that using this questionnaire is easy, and its generalizability depends on sample size and study population characteristics. In conclusion, the Persian version of the HCEQ shows good reliability as well as face validity, and content validity. The analysis of construct validity through EFA presented a satisfactory model. Our study also confirmed that HCEQ-10/PV in the determination of healthcare empowerment score and related domains to provide relevant educational materials are more appropriate and timely needed. Setting suitable health promotion intervention programs among women in reproductive age is a future research intention.

\section{ACKNOWLEDGMENTS}

The authors express their gratitude to all women who participated in the study. We would also like to express our special gratitude to Tehran University of Medical Sciences for funding this study with grant number 33636 .

\section{REFERENCES}

1. Kameda Y, Shimada K. Development of an empowerment scale for pregnant women. Tsuruma Health Science Society Kanazawa University 2008; 32: 39-48.

2. WHO Guidelines on Hand Hygiene in Health Care: First Global Patient Safety Challenge Clean Care Is Safer Care. Available from:

http://www.who.int/healthpromotion/about/HPR\% 20Glossary\%201998.pdf

3. WHO. WHO- MDG3: promote gender equality and empower women. Available from:http://www.un.org/millenniumgoals/gender.s html (Accessed on 2 August 2017)

4. Management and Planning Organization of Iran (MPO). The First Millennium Development Goals Report. $1^{\text {st }}$ edition, MPO\& UN: Tehran, 2004 [Persian version].

5. Nikbakht Nasrabadi AR, Sabzevari S, Neghban Bonabi T. Women Empowerment through Health

DOI: http://dx.doi.org/10.4314/ejhs.v28i3.12 
Information Seeking: A Qualitative Study. Int $J$ Community Based Nurs Midwifery 2015;3(2): 105.

6. Bayati M, Feyzabadi VY, Rashidian A. Geographical Disparities in the Health of Iranian Women: Health Outcomes, Behaviors, and Healthcare Access Indicators. Int J Prev Med. 2017; 8:11.

7. Andrew M. choices for women: planned pregnancies, safe birth and Healthy maternal and newborn Health in the newborns.

Availablefrom:https://www.gov.uk/government/up loads/system/uploads/attachment_data/file/67640/ RMNH-framework-for-results.pdf (Accessed on 2 August 2017)

8. Birtta CM, Michelle J. Can women's autonomy impede male involvement in pregnancy, Health in katamando, Nepal? J social science and medicine. 2005; 61(9): 1993-2006.

9. Song LY.Service utilization, perceived changes of self, and life satisfaction among women who experienced intimate partner abuse: the mediation effect of empowerment. $J$ Interpers Violence. 2012; 27(6):1112-36.

10. Silvestre G, Landa U. Women, Physical Activity, and Quality of Life: Self-concept as a Mediator. Span J Psychol. 2016; 22; 19:E6.

11. Bilajac L, Marchesi VV, Tesic V, Rukavina T. Life satisfaction, optimism and social capital as predictors of mental health of the recipients of financial welfare from the state. Psychiatr Danub. 2014; 26 Suppl 3:435-41.

12. Mitroi LR, Sahak M, Sherzai AZ, Sherzai D. The Women's Health Care Empowerment Model as a Catalyst for Change in Developing Countries. Health Care Women Int.2016;37(3):273-87.

13. Herbert RJ, Gagnon AJ, Rennick JE, O'Loughlin JL. A Systematic Review of Questionnaires Measuring Health-Related Empowerment. Res Theory Nurs Pract. 2009; 23: 107-132.

14. Tol A, Sharifirad GR, Pourreza AG, Rahimi A, Shojaeezadeh D, Mohrajeritehrani MR, et al. Development of a valid and reliable diabetes empowerment scale: An Iranian version. Iran Red Crescent Med J. 2012; 14: 305-8.

15. Hibbard JH, Stockard J, Mahoney ER, Tusler M. Development of the Patient Activation Measure (PAM): conceptualizing and measuring activation in patients and consumers. Health Serv Res. 2004; 39: 1005-1026.
16. Gagnon $M$, Hebert $R$, Dube $M$, Dubois $M$. Development and validation of an instrument measuring individual empowerment in relation to personal health care: The health care empowerment questionnaire (HCEQ). American journal of Health Promotion.2006; 20(6):429-435.

17. Streiner DL. Starting at the beginning: an introduction to coefficient alpha and internal consistency. J Pers Assess 2003; 80(1):99-103.

18. Kaiser HF. An Index of Factorial Simplicity. Psychometrika 1974; 39: 131-36.

19. Dixon JK. Exploratory Factor Analysis. In: Munro, B., Ed., Statistical Methods for Health Care Research, Lippincott Williams \& Wilkins Publisher, Philadelphia 2005; 321-49.

20. Kaiser HF. The Application of Electronic Computers to Factor Analysis. Educational and Psychological Measurement 1960; 20: 141-151.

21. Costello AB, Osborne JW.Best Practices in Exploratory Factor Analysis: Four Recommendations for Getting the Most from Your Analysis. Practical Assessment Research and Evaluation 2007; 10: 1-9.

22. Stone AT, Bransford RJ, Lee MJ, Vilela MD, Bellabarba C, Anderson PA, et al. Reliability of classification systems for sub-axial cervical injuries. Evid Based Spine Care J 2010; 1(3):1926.

23. Cyril SH, Smith BJ, Renzaho AMN. Systematic review of empowerment measures in health promotion. Health promotion international 2016;31(4):806-826.

24. Aujoulat I, d'Hoore W, Deccache A. Patient empowerment in theory and practice: Polysemy or cacophony? Patient education and counseling 2007; 66: 13-20.

25. Tol A, Alhani F, Shojaeazadeh D, Sharifirad Gh. Empowerment approach to promote quality of life and self-management among type 2 diabetic patients. Health System Research 2011; 7(2): 157168 [Persian Version].

26. Tol A, Baghbanian A, Mohebbi B, Shojaeizadeh D, Azam K, Esmaeeli Shahmirzadi S, Asfia A. Empowerment assessment and influential factors among patients with type 2 diabetes. Journal of Diabetes \& Metabolic Disorders, 2013; 12:6. 